\title{
Feasibility and Countermeasures of Promoting Harmonious and Beautiful Rural Construction with Traditional Chinese Medicine Culture
}

\author{
Li Wang \\ Jiangxi University of Traditional Chinese Medicine \\ Nanchang, Jiangxi, China
}

\author{
Qiao Liu \\ Jiangxi University of Traditional Chinese Medicine \\ Nanchang, Jiangxi, China
}

\author{
Suzhen $\mathrm{Yu}^{*}$ \\ Nanchang Institute of Science \& Technology \\ Nanchang, Jiangxi, China \\ *Corresponding author
}

\begin{abstract}
Based on the purpose for exploring the feasibility and countermeasures of promoting harmonious and beautiful rural construction with traditional Chinese medicine culture, this work analyzed the policy, resources and industry of traditional Chinese medicine in combination with literature and research. Suggestions are put forward from the perspectives of creating planting landscape, developing traditional Chinese medicine agriculture, promoting communication culture and cultivating rural tourism brand, etc. The research is of great significance for innovating the path on China's rural revitalization strategy.
\end{abstract}

Keywords-Traditional Chinese medicine culture; Harmonious and beautiful countryside; Rural tourism; Countermeasures

\section{INTRODUCTION}

The report of the 19th CPC National Congress put forward the strategy on implementing rural revitalization. It should persist in taking the priority development of agriculture and countryside as the foundation, establish and perfect the system mechanism and policy system of urban and rural integration development, and speed up the modernization of agriculture and the countryside. Governments at all levels actively respond to the general requirements of the Party Central Committee for rural development, such as prosperous industry, livable ecology, civilized rural customs, effective governance and rich life.

\section{HARMONIOUS AND BEAUTIFUl RURAL CONSTRUCTION}

\section{A. The connotation of harmonious and beautiful rural} construction

In 2012, the People's Government of Jiangxi Province formally put forward the new concept on "harmonious and beautiful countryside" in Several Opinions on Implementing Harmonious and Beautiful Rural Construction Project. It is the province to actively adapt to the current economic and social development trend at home and abroad, adapt to the rural social transformation and give full play to Jiangxi's rural advantages. It is an important measure to promote the harmonious coexistence of rural economy, society and nature and build a better new socialist countryside with systematic thinking and overall planning. The main purpose is to enrich the rural mass culture, promote the prosperity of farmers, accelerate the progress of rural civilization, and better meet the farmers' yearning for a better life by improving the working and living environment in the countryside.

\section{B. An overview of harmonious and beautiful rural construction}

In recent years, the local governments of Jiangxi Province have paid attention to the combination of local geographical conditions, cultural characteristics and resource advantages in implementing the harmonious and beautiful rural construction project. For example, in Fuliang County, through environmental renovation, river cleaning, construction into the township archway, roadside lawn, leisure park, etc., the village has taken on a new look. Hengfeng county makes full use of natural and cultural resources such as terraced fields, paper-cutting, etc., to launch the "one-day tour in Hengfeng countryside" project. In Wuning county, the ecological living environment for farmers was built by renovating roads, changing water and toilets, renovating houses, etc. Through playing green organic and ecological advantages as a whole, Jingan County vigorously develops green organic agriculture, promotes the construction of "agricultural and residential culture", and realizes the enrichment of industry and ecology. These measures have enabled the vast number of farmers to walk flat roads, drink clean water, live in clean houses, and lay a basic and complete new life on the Internet [1].

Although some achievements have been made in the construction of "harmonious and beautiful countryside" at present, it can't ignore the problems such as the difficulty of rural style and civilization, the weakness of industry drive, the heavy task of poverty alleviation, etc. For example, most villages have carried out housing layout planning, updated infrastructure and rectified dilapidated houses at present. However, the living habits, humanistic quality and health literacy of farmers can not fit the new environment. Therefore, 
the phenomenon of "only seeing new villages, but not new features" appears [2].

Secondly, in the process of building a harmonious and beautiful countryside, Jiangxi Province failed to effectively integrate and highlight the main industrial characteristics and resource characteristics. As a result, the industrial driving ability is not strong. The income increase of farmers is difficult, and the targeted poverty alleviation ability is weak.

\section{The FeAsibility OF PROMOTING "HARMONIOUS AND BEAUTIFUL RURAL CONSTRUCTION" WITH TRADITIONAL CHINESE MEDiCine CULTURE}

\section{A. The concept of Chinese medicine culture}

In the excellent traditional culture of the Chinese nation, traditional Chinese medicine culture is the sum between spiritual civilization and material civilization that embodies the essence and characteristics of traditional Chinese medicine. In a broad sense, traditional Chinese medicine culture includes a wide range of social environment, thinking mode and philosophy [3], including traditional Chinese medicine resources, traditional Chinese medicine industry, traditional Chinese medicine policies, and traditional Chinese medicine spirit, etc. Traditional Chinese medicine culture can not only meet people's basic needs of understanding life, maintaining health and preventing and treating diseases. At the same time, the emerging business forms formed by the organic combination with traditional Chinese medicine, pensions, tourism, health management, etc., are of great significance to promote the integration of rural primary, secondary and tertiary industries, and support and encourage employment and entrepreneurship for farmers. It is of great significance to broaden income channels, consolidate targeted poverty alleviation, and become an important engine for rural revitalization and development.

\section{B. An analysis on the conditions for the integration of}

traditional Chinese medicine culture into "harmonious and beautiful rural construction"

\section{1) Superior natural conditions}

In terms of geological soil, Jiangxi belongs to a subtropical monsoon climate, with high forest coverage, abundant rainfall and sunshine. The soil in Jiangxi is mainly composed of subtropical evergreen broad-leaved forest red soil and yellow soil, which is rich in Hilly and mountainous resources and good planting conditions. At present, there are more than 3000 kinds of traditional Chinese medicine resources in Jiangxi, including 20 kinds of well-known traditional Chinese medicine. Among them, Semen Plantaginis and Fructus Aurantii accounted for $70 \%$ and $25 \%$ of the total output respectively. 11 Chinese herbal medicines, such as Zhangshu Evodia officinalis, Jinxi Gardenia jasminoides and Dexing Dendrobium candidum, etc., have been protected by national geographic indications.

\section{2) Strong policy support}

The Government of Jiangxi Province has promulgated The Development Plan of Traditional Chinese Medicine Health Service in Jiangxi Province (2016-2020), Several Opinions on People's Government of Jiangxi Provincial with Accelerating the Development of Traditional Chinese Medicine, The
Development Plan of Traditional Chinese Medicine in Jiangxi Province During the 13th Five Year Plan, The Implementation Opinions on Promoting the Development of Thermal Moxibustion Industry, etc. It is proposed to take innovation and upgrading as the main line of development and take multiple economic components as the main body of development. Efforts should be made to promote the combination of primary, secondary and tertiary industries. The core competitiveness and market share of the traditional Chinese medicine industry in the province should be constantly improved, and efforts should be made to build a strong province of traditional Chinese medicine [4].

\section{3) Rich cultural resources}

Jiangxi Province, with its profound traditional Chinese medicine, is one of the important birthplaces of Chinese medicine culture and technology. It is also an important concentration and distribution center for the planting and processing of traditional Chinese medicine. Fuzhou City occupies an important position in the history of Chinese medicine. Since the Han Dynasty, more than 970 famous traditional Chinese medicine scholars have been born, and more than 680 medical books with a specific purpose have been compiled. Jianchang Gang and Zhangshu Gang, Jing Gang and Chuan Gang are the four traditional Chinese medicine processing schools in China. Since ancient times, there has been a saying that "if the medicine is less than Zhangshu, it will not work well in Jianchang". At present, Jiangxi is also actively developing tourism scenic spots with traditional Chinese medicine health preservation culture as the foundation, such as the health preservation hot spring resources represented by West Sea, Mount Lu hot spring and Linquan hot spring. Zhangshu, the pharmaceutical capital, is building modern cultural tourism areas with traditional Chinese medicine and health care as the theme, such as the historical and cultural block of the three imperial palaces, which is based on the medical care and health-care tourism [5].

\section{4) Rapid industrial development}

Jiangxi has a large number of traditional Chinese medicine advantage enterprises, such as Jimincare, CR Jiangzhong, Jiangxi side, etc. the products of traditional Chinese medicine have certain popularity and market share in the country. In 2017, the main business income of the traditional Chinese medicine industry ranked fourth in China, and the main business income of proprietary Chinese medicine ranked third in China. At the same time, Shangrao city was selected as one of the first batch of "national traditional Chinese medicine health tourism demonstration areas". Traditional Chinese medicine health tourism has gradually become a new business card of "unique scenery in Jiangxi" and another "new force" of building a province strong in traditional Chinese medicine.

\section{Countermeasures AND Suggestions of Promoting \\ "HARMONIOUS AND BEAUTIFUL RURAL CONSTRUCTION" With TRAditional CHINESE MEDICINE CULTURE}

\section{A. Creating a landscape for planting traditional Chinese} medicine and building a beautiful ecological countryside

According to the characteristics of local natural conditions and the principle of adjusting measures to local conditions, 
each region can reasonably plan and design the rural infrastructure construction, create the landscape of traditional Chinese medicine planting and expand the planting area of traditional Chinese medicine. For example, relying on abundant resources and technologies of traditional Chinese medicine, Fuzhou city has built nearly 200 kilometers of traditional Chinese medicine health tourism demonstration belt along the Fuyin, Fuji and Ziguang expressways. Several industrial cultivation bases and agglomerations of genuine Chinese herbal medicines have been constructed. The varieties of Hedyotis diffusa, Gardenia, Torreya grandis, Alisma orientalis, Eucommia, Salvia miltiorrhiza, Honeysuckle and Paeony were selected for planting. It should beautify rural roads, build ecological civilization villages and improve the attraction and stop rate of tourists.

\section{B. Promoting traditional Chinese medicine health concept and promoting rural civilization and harmony}

Traditional Chinese medicine culture and socialist core values share the same cultural gene. The holistic view of the unity between heaven and man, the health view of the peace between yin and Yang, the treatment view of harmonizing and giving to the middle school, and the moral view of the doctor-patient's trust and the same way and modesty were carried forward. The farmers' understanding and practice of harmony between man and nature and between man and man are promoted. Through extensive in-depth grass-roots development of traditional Chinese medicine health culture education, traditional Chinese medicine health culture knowledge and traditional Chinese medicine health and disease prevention knowledge training into thousands of households. The majority of farmers have been promoted to develop healthy living habits, and their health literacy and self-awareness of health care have been improved. It is of great positive significance to cultivate and practice the socialist core values, improve the health literacy of farmers in traditional Chinese medicine, build a good rural tourism environment, and promote rural civilization and harmony.

\section{Strengthening the support of the government and cultivating the characteristic rural tourism brand}

To build a harmonious and beautiful countryside, the government should increase its support. Through the introduction of capital, technology and talents, the government should support and improve the medical infrastructure in the countryside. A health care service area with traditional Chinese medicine characteristics in the rural areas, such as health-care small town, heat-sensitive moxibustion small town, health care and elderly care comprehensive park of traditional Chinese medicine, experience area with traditional Chinese medicine characteristics, national heritage base of famous and old Chinese medicine, traditional Chinese medicine museum, etc., should be set up. We should further study the tourism projects and series products with the characteristics of Jiangxi traditional Chinese medicine culture brand, and expand the supply chain and product chain of rural tourism. For example, since ancient times, Jiangxi has a deep cultural origin with Confucianism, Buddhism and Taoism. Confucianism, Buddhism and Taoism are integrated into the traditional Chinese medicine culture, and they interact with other natural and human tourism resources. They have been learned and accepted by the Chinese people since they were young [6]. Therefore, traditional Chinese medicine culture can be carried forward through promoting Confucianism, Buddhism and Taoism culture, thus creating a characteristic rural tourism brand in Jiangxi Province.

\section{Actively spreading traditional Chinese medicine culture and building a beautiful village with wisdom}

In the construction of harmonious and beautiful countryside, it is suggested to beautify the house based on "aesthetic system" and take the initiative to implant the content of traditional Chinese medicine culture communication. In the outer walls of rural houses, famous sayings of ancient Chinese medicine can be painted, such as Li Shizhen, Zhang Zhongjing and other famous Chinese medicine experts. It can also spread all kinds of traditional Chinese medicine atlas, traditional Chinese medicine allusions and traditional Chinese medicine health preservation knowledge on the outer wall in the building or on the billboard. In the rural tourism environment, the atmosphere of traditional Chinese medicine culture is created, and tourists' experience of traditional Chinese medicine culture is enhanced. At the same time, AR or AI technology can be used to spread traditional Chinese medicine cultural tourism projects and improve the experience and participation of tourists. Tourists can enhance their personal feelings through the integration of beautiful countryside with traditional Chinese medicine cultural tourism [7]. Through the big data platform, the potential health needs of tourists can be mined in time. According to the personalized needs of tourists, relevant products are pushed, such as moxibustion, medicine bath, cupping and other health care services.

\section{E. Developing traditional Chinese medicine agriculture and promoting the income of farmers from poverty}

As a potential economic resource, traditional Chinese medicine can realize the creative transformation of traditional Chinese medicine culture, and promote the development of traditional Chinese medicine industry through scientific and technological innovation. By integrating traditional Chinese medicine with modern science, technology and industry, conducting research across disciplines and industries, and breaking the boundaries between industries and units, more traditional Chinese medicine products and technologies can be created. This will play a greater role in solving the employment of the poor. For example, Shangrao city, Jiangxi Province, encourages farmers to plant traditional Chinese medicine in promoting the health tourism planning of traditional Chinese medicine. It is a good example for farmers to carry out the cultivation training of traditional Chinese medicine, develop the cultivation and deep processing of traditional Chinese medicine, and build a traditional Chinese medicine industrial park.

In short, the strategy for rural revitalization needs the driving force from culture. In policy, culture and industry development status, the traditional Chinese medicine culture in Jiangxi Province has the feasibility in promoting the harmonious and beautiful rural construction. Based on traditional Chinese medicine planting, health service, cultural communication, etc., the innovative development of harmonious and beautiful rural construction can be promoted. 
[5] Mu Liang, Yao Dongming. Research on Human Resources Development with Traditional Chinese Medicine Health Tourism in Jiangxi Province Based on SWOT Analysis [J]. Human Resources, 2016,11 (549): 132-133.

[1] Peng Feng. Discussion on the Beautiful Countryside and Rural Tourism in Jiangxi [J]. Urban and Rural Construction, 2018 (07): 34-37.

[2] Zhou Xiaotao. Problems and Suggestions on the Construction of "Beautiful Villages" [EB/OL]. (2017-12-18). http: // www. jxsrrd. gov.cn / 2017 / 1218 / 3639. shtml.

[3] Gao Min, Xu Mingyuan. Connotation and Function of Chinese Medicine Culture. Journal of Chinese Medicine Management, 2012, 7 (20): 629-630.

[4] Xie Yuxin. Leveraging Advantages Jiangxi Strives to Build a Strong Province of Traditional Chinese Medicine [EB/OL]. (2018-07-02). http: // www. cinn. cn / headline / 201807 / t20180702_194770. html.

[6] Li Xian, Huang Kai, Sun Han, Yu Shuangyan. SWOT Analysis of Cultural Tourism with Traditional Chinese Medicine in Jiangxi Province [J]. Journal of Traditional Chinese Medicine Management, 2017, 37 (10): 1195

[7] Wang Li, Liao Yawen, Chen Sisi, Sun Jianqiang. Research on the Strategy in Realizing the Value of Health Tourism Resources with Traditional Chinese Medicine in Shangrao City [J]. Consumer Guide, 2018 (23): 69 